\title{
Occurrence of Veterinary Drug Residues in Poultry and Products Thereof. A Review
}

\author{
Maxim Bobkov and Pascal Zbinden
}

\begin{abstract}
Over the past decades, great efforts in poultry management have led to a tremendous uplift in the productivity of poultry production. This progress, coupled with the intensification of production, has created the potential for diseases in birds as their energy is fully oriented towards productivity but not to resistance. In order to prevent or treat the diseases, biosecurity measures and vaccination are widely applied; nevertheless, medication is still widely practiced worldwide. Information on influencing factors and use of veterinary medicinal products in poultry industry as well as data on detection of residues in poultry products were collected from various sources. The data obtained were analyzed and ranked to represent a likelihood of occurrence of substances to be monitored in poultry and products thereof.
\end{abstract}

Keywords: Drugs $\cdot$ Monitoring $\cdot$ Poultry $\cdot$ Residue $\cdot$ Veterinary medicinal products

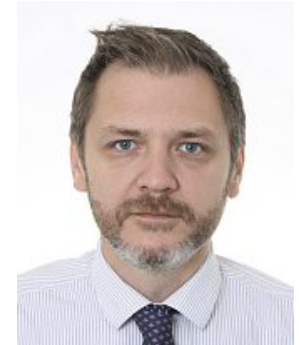

Maxim Bobkov is an expert in food safety at Nestlé Research Center. He has regulatory and quality management experience in different food industry sectors. He is also actively involved in the international standard setting process and is a member of the International Dairy Federation and of the FoodDrinkEurope. $\mathrm{He}$ is a veterinary and sanitary doctor by training and holds a $\mathrm{PhD}$ in the domain of veterinary public health.

\section{Introduction}

Residues may occur in edible tissues from the exposure of poultry to contaminants or additives in feed as well as a result of possible administration of authorized or non-authorized veterinary medicinal products. ${ }^{[1]}$ Veterinary drugs are used in poultry for therapy and for prophylaxis that may encompass control and prevention of diseases, ${ }^{[2]}$ assistance in relieving stress ${ }^{[3]}$ and, in certain countries, acceleration of growth. ${ }^{[4]}$ It is estimated that $80 \%$ of all food-producing animals receive medication for a part or most of their life. ${ }^{[5]}$ Usually, while the

\footnotetext{
${ }^{*}$ Correspondence: Dr. M. Bobkov

Nestlé Research Centre

Institute of Food Safety and Analytical Science

Vers-chez-les-Blanc, Route du Jorat 57

$\mathrm{CH}-1000$ Lausanne 26

E-mail: maxim.bobkov@rdls.nestle.com
}

recommended dosage and withdrawal time are respected, residue levels in edible tissues do not exceed the regulatory limits, but results of national residue monitoring in different countries show that the reality is far from perfect. Global trade is increasing and flow of products, including poultry, is constantly changing. ${ }^{6]}$ In order to comply with local and international regulatory requirements, the food industry needs a more transparent global view on the residue occurrence in poultry raw materials. This would allow precise control despite of raw material origin and guarantee compliance of finished products in the countries of sales. Implementation of multi-residue screening methods complements assurance in compliance and safety of final products for consumer, but screening for certain substances should be substantiated as far as possible. This would potentially allow the set-up of cost-effective analytical monitoring.

The development of a monitoring plan for residues of veterinary medicinal products, which would consider all substances that could potentially be detected in particular commodity of animal origin, would definitely help the food industry in modern conditions of global trade, when the origin of raw material is difficult to trace.

In order to evaluate and address the likelihood of occurrence for veterinary drug residues in poultry and products thereof, information on factors which influence the use of veterinary medicinal substances in poultry as well as results of official residue monitoring programs were collected and analyzed. Some diversity and some similarities in residue occurrence of veterinary medicinal products in poultry products were found in different parts of the world despite the limited available in- formation. Diversity could be explained by the difference in legal requirements for use of the same drugs in farmed animals from country to country, as well as by the variety of different medicinal products authorized and different veterinary practices applied around the globe, while similarities arise in the common targets and issues in the poultry industry regardless of geographical location, as well as by globalization of feed/food and pharmaceutical trade.

Egg production, eggs and products thereof were excluded from this review. The term 'poultry' is used to refer to any farmed avian species that has the potential for its meat, byproducts and products thereof to directly or indirectly enter the food chain.

\section{Background}

Over the last 50 years, great efforts in genetics (conventional breeding) and improvements in poultry management have led to a tremendous increase in the productivity of poultry production. ${ }^{[7]}$ In the $1940 \mathrm{~s}, 6.8 \mathrm{~kg}$ of feed over a 15 week period were necessary to produce a $1.4 \mathrm{~kg}$ chicken. Today, a chicken weighing $2.0 \mathrm{~kg}$ can be produced in less than 7 weeks with about $3.8 \mathrm{~kg}$ of feed. These are the consequences of a continuing effort to increase productivity, which has allowed access to low-price poultry meat for the majority of the worldwide population. This progress, coupled with the intensification of production, has created the potential for infection in birds, which may be in a weakened state - as their energy is fully oriented towards productivity but not to resistance. ${ }^{[8]}$ The difference is clearly illustrated in Fig. $1 \mathrm{a}$ and $\mathrm{b}$. 

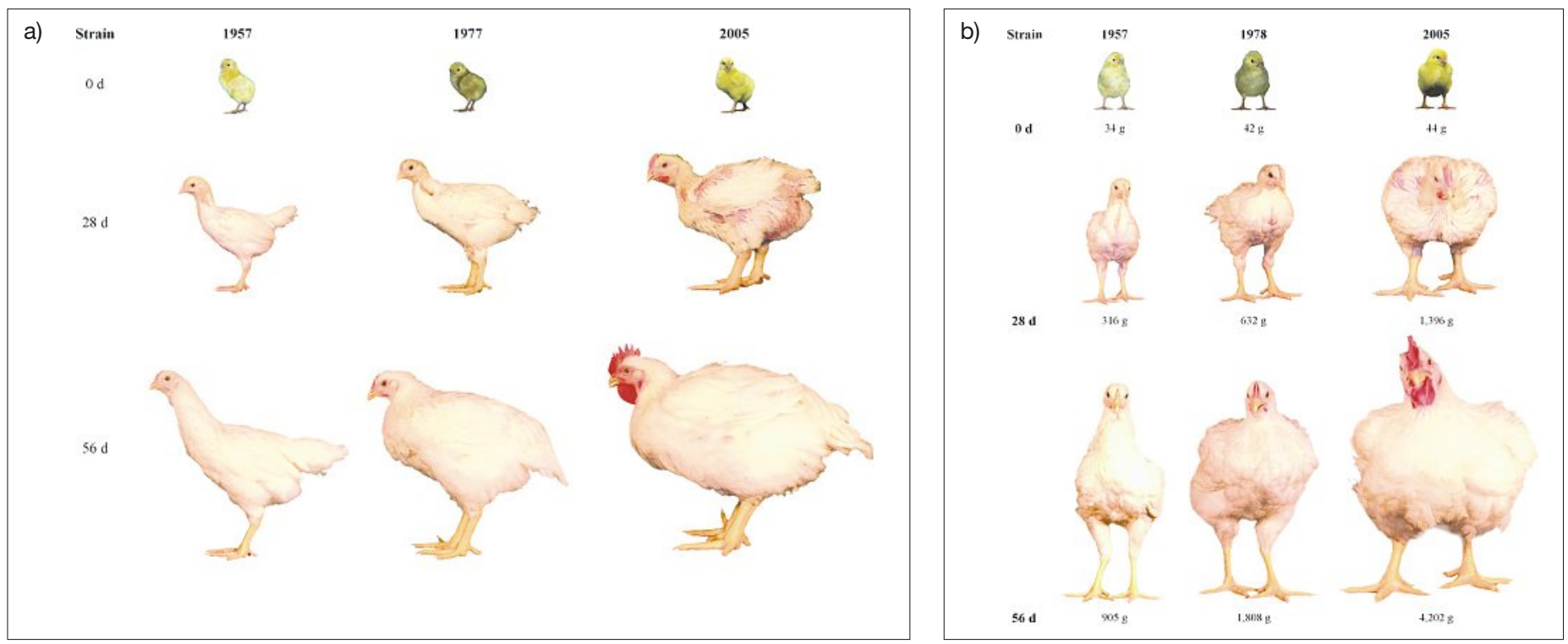

Fig. 1. Age-related changes in size of University of Alberta Meat Control strains unselected since 1957 and 1978, and Ross 308 broilers (2005).

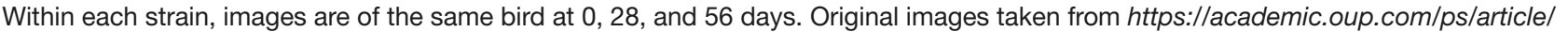
93/12/2970/2730506. ${ }^{[7]}$ ()2014 Poultry Science Association Inc.

The conditions of the birds' life directly impact their health. Currently, there are more chickens in the world than any other birds, but unlike other birds which live in freedom, most chickens are kept in overcrowded sheds. Two thirds of farmed chicken are factory grown. Globally, $70 \%$ of meat chickens are raised in intensive farming systems and will have more space in the oven being cooked than when they were alive. ${ }^{[9]}$ Keeping the birds in close conditions increases the health risks associated with a lack of physiological movement and definitely increases the potential for the fast spread of any contagious disease in the event of an outbreak.

Economic losses to poultry diseases are currently $10-20 \%$ of the gross value of production in developed poultry industries, and are likely to be higher in developing countries. ${ }^{[10]}$ Information about the health vulnerabilities of poultry gives a hint of the spectrum of veterinary medicinal products used in farmed birds. The working partnership for addressing animal diseases between the Institute for Animal Health, UK; The Food and Agriculture Organisation of the United Nations (FAO); World Organisation for Animal Health (OIE) and Telos ALEFF Ltd., UK, the 'AVIS consortium', listed respiratory organs, intestinal tract and musculoskeletal system as the main bird vulnerabilities. Respiratory organs and intestinal tract are in direct contact with the environment and are an entry point for infectious agents, while joints and legs are anatomical weak points for meat-producing poultry. If bird movements are not enabled and the birds do not support their weight, illness, mortality and (at least) loss of productivity will result. ${ }^{[7]}$

Different veterinary drugs are currently used in poultry production systems to treat birds' health vulnerabilities and fight the associated causative agents: bacteria, viruses, parasites and fungi; to treat stress and disabilities of the musculoskeletal system as a result of intensive breeding or improper husbandry practices. It should not be forgotten that cost effectiveness in poultry production forces industry to try a variety of means to enhance birds' growth and performance.

Incorrect use of veterinary drugs such as overdose, inappropriate lengths of use, failure to follow the label instructions and poor observance of withdrawal periods prior to slaughter may leave residues of drugs in tissues at concentrations above regulatory limits and in some cases that may be harmful to human health. ${ }^{[11,12]}$ Presence of residues of veterinary drugs could also occur from a reluctance to seek veterinary care ${ }^{[13]}$ leading to unsupervised administration of drugs.

Different animal tissues are used in routine control of veterinary drug residues. In raw poultry products, veterinary drug residue concentrations tend to be higher in liver and kidney than in the muscle ${ }^{[14]}$ and therefore residues should be controlled in both matrices. However, there are also a lot of processed materials that are used as ingredients in industrial food products. The question whether residues should be controlled in processed products remains for many specialists taking into account the well known fact that cooking procedures and freezing cause some degradation of a number of drugs. Veterinary drugs vary in their susceptibility to degradation at common processing temperatures. ${ }^{[15,16]}$ The concentration after partial degradation in muscles or other tissues containing residues is subject to large variation due to different factors. There are no predictive models developed for drug residues in processed products, therefore residues which are monitored in unprocessed materials should also be monitored in processed products.

\section{Methodology}

Data on poultry health vulnerabilities were used as a starting point and compiled with data on use of veterinary drugs and available results on positive residue detections. Data were collected from various sources at international level: OIE, FAO, and results of national monitoring plans. Development of an efficient monitoring plan is essential for assurance of safety and compliance of the food products. Results of national monitoring plans were analyzed and a likelihood of occurrence was attributed to groups of residues and for particular substances.

The likelihood of occurrence for residues of veterinary pharmaceutical products in poultry and products thereof was attributed according to the following principles:

a) High likelihood of occurrence: residues of veterinary drugs have a well recognized association with poultry. Use of veterinary medicinal products in poultry production systems was confirmed and presence of residues in poultry products was repeatedly confirmed in results of national monitoring plans.

b) Medium likelihood of occurrence: residues of veterinary drugs have a potential association with poultry while evidence is limited or not yet demonstrated. Use of veterinary medicinal products in poultry production systems was confirmed but residues were never or rarely detected during control.

c) Low likelihood of occurrence: residues of veterinary drugs have a weak asso- 
ciation with poultry. This includes substances that are naturally present (such as hormones) or residues that may occur in poultry products by an indirect path (such as insecticides used to treat the environment).

Evaluation for residues of different pharmaceutical classes and particular substances in poultry and products thereof was limited by publically available information on official control and results of national monitoring plans. In this review, the following data were considered: European Union results of national residue monitoring (2006-2015), ${ }^{[17]}$ and Rapid Alert System for Food and Feed (EU RASFF) alerts (2007-2017), ${ }^{[18]}$ and with data collected over different time periods from national residue monitoring plans of United States of America (2001-2014), ${ }^{[19]}$ Canada (2010-2014), [20] and Australia (20112014).[21]

\section{Results}

Veterinary medicinal products are widely used in poultry production. Information on occurrence of residues of veterinary drugs vary a lot due to different veterinary practices and systems of veterinary drug residue control, developed considering national practices and information collected from importing countries.

\subsection{Antimicrobial Agents}

Antimicrobial agents are the largest group of important veterinary medication used in poultry. In the absence of ultimate global traceability for raw materials and in the absence of a global database of veterinary drugs registered for legal use in different countries, the 'OIE list of antimicrobials of veterinary importance' ${ }^{[22]}$ was used for comparison with results of national monitoring plans. The list was developed in 2007 as one of the steps towards fighting antimicrobial resistance, with further refinement and adoption in 2013 and 2015. It is based on the data from food and veterinary controlling authorities of OIE member-countries representing all geographical zones and considering two main criteria: (1) more than $50 \%$ of the countries identified the importance of the antimicrobial class in veterinary practice and (2) compounds within the class are identified as essential against specific infections with a lack of sufficient alternatives. The list includes substances legally approved in some countries and banned in others as well as antimicrobials used in some countries in poultry as performance enhancers (so-called 'growth promoters'). Use of this list in this evaluation was based on the assumption that substances mentioned and allocated to treatment of avian species on it are widely used in poultry production systems around the world and there is a significant probability of detecting their residues in poultry products. Special consideration was paid to the substances not included on the OIE list but detected in poultry products during national monitoring.

All the substances mentioned in the OIE list were ranked at medium likelihood of occurrence unless positive detections were reported. All substances ever reported in positive results of national residue monitoring were ranked with high likelihood of occurrence. Results of analyses are compiled in Table 1.

\subsection{Antiviral Substances}

Despite the wide variety of viral diseases in poultry, the use of chemical antiviral substances in poultry production systems is linked to the prevention or/and treatment of avian influenza. Although the presence of antivirals in poultry and egg products is not officially regulated in many countries, their wide use to prevent/treat avian influenza in poultry was opposed by international organizations ${ }^{[23]}$ due to possible development of antimicrobial resistance.

The most known and discussed case of wide use of antivirals is the administration of amantadine against avian flu in poultry in China. ${ }^{[24]}$ It seems that its use is still ongoing in different countries due to certain, mostly economic reasons. ${ }^{[25-27]}$

Many substances can be used to control viral diseases. Amantadine was and still is a detected substance in products of poultry origin, but there are other substances reported in the scientific literatute ${ }^{[28,29]}$ as suitable for treatment of avian influenza in poultry. Substances other than amantadine are not used widely due to their limited availability, lower efficiency or higher prices. The likelihood of occurrence for antiviral substances is summarized in Table 1.

\subsection{Substances Used against Parasitic Diseases: Anticoccidials, Antihelminthics and Insecticides}

Parasitic diseases continue to be of great concern in deep-litter and free-range commercial systems. In traditional systems, a number of parasites are widely distributed and contribute significantly to low productivity worldwide. ${ }^{[30]}$ The main problems in poultry production associated with parasites are coccidiosis, intestinal worms, lice and mites. The likelihood of occurrence for anti-coccidials is summarized in Table 2.

\subsubsection{Anticoccidial Substances}

Worldwide the poultry industry spends a significant amount of money for the prevention and treatment of several diseases, one of which is avian coccidiosis. ${ }^{[31]}$ It would not have been feasible to develop the modern chicken and turkey industries without the discovery and use of anti-coccidials. ${ }^{[32]}$ The OIE defines anticoccidials, including arsenicals, and especially ionophores, as drugs critically important for veterinary use and particularly for poultry. ${ }^{[22]}$ Drugs known as anticoccidials come from a number of different pharmaceutical classes. It should be noted that many antimicrobials are used as anticoccidials, such as nitroimidazoles and sulfonamides, but they have been already covered in the section 4.1 'Antimicrobial Agents'.

According to results of national residue monitoring programs, numerous incidents of non-compliance have occurred in the recent past, so these compounds continue to be of concern. In the EU, the results for poultry in 2011-2015 showed that noncompliant results for anticoccidials represent $0.15-0.22 \%$ of analyzed samples and $20-29 \%$ of the non-compliant results recorded across all groups of substances each year, following non-compliant results for antimicrobials. If the most detected anticoccidial nicarbazin results are discounted in EU national residue monitoring in 2005-2010, the ionophore group: lasalocid, maduramicin, salinomycin and monensin account for approximately $70 \%$ of the non-compliant results; for the non-ionophoric group: diclazuril and robenidine are most detected, with occasional detections of amprolium, clopidol, decoquinate and toltrazuril sulfone.[1] The situation seems to be similar all over the world even in the absence of a full picture for some countries: according to EU RASFF reports anticoccidials were reported in poultry samples from Brazil, China and Israel. Canadian results repeat the EU pattern.

Arsenicals are also used to control coccidiosis in poultry, but data on their use are not presented in national residue monitoring results; data on their sales unfortunately is not available either. Despite being non-approved in the EU and withdrawal of approval for the last arsenical, nitarsone, in 2015 in USA, ${ }^{[33]}$ the OIE still mentions arsenicals roxarsone and nitarsone as drugs of importance. Despite the absence of reported positives, in Australia, ${ }^{[34]} \mathrm{Canada}^{[35]}$ and other countries, e.g. China and Peru, arsenicals are still approved for poultry production.

\subsubsection{Anthelmintic Substances}

Treatment against three main worm classes (nematodes, trematodes and cestodes) in order to eradicate helminthiases is applied in poultry production systems all over the world. Certain limited information is available from anthelmintic substance studies in poultry production: benzimidazoles (flubendazole, albendazole and fenbendazole), levamisole, piperazine and ivermectin. ${ }^{[12,14]}$ 
Table 1. Likelihood of occurrence for antimicrobial agents and antiviral substances in poultry and products thereof.

\begin{tabular}{|c|c|c|c|}
\hline $\begin{array}{l}\text { Pharmaceutical class } \\
\text { of substances }\end{array}$ & High likelihood of occurrence & $\begin{array}{l}\text { Medium likelihood } \\
\text { of occurrence }\end{array}$ & Low likelihood of occurrence \\
\hline Aminoglycosides & dihydrostreptomycin & $\begin{array}{l}\text { spectinomycin, streptomycin, } \\
\text { kanamycin, neomycin, paromo- } \\
\text { mycin, apramycin, fortimycin, } \\
\text { gentamicin }\end{array}$ & \\
\hline Amphenicols & chloramphenicol & thiamphenicol, florphenicol & \\
\hline Nitrofurans & $\begin{array}{l}\text { nitrofurazone, furaltadone, fura- } \\
\text { zolidone, nitrofurantoin }\end{array}$ & & \\
\hline Quinolones & $\begin{array}{l}\text { flumequin, oxolinic acid, cipro- } \\
\text { floxacin, difloxacin, enrofloxa- } \\
\text { cin, sarafloxacin }\end{array}$ & $\begin{array}{l}\text { danofloxacin, marbofloxacin, } \\
\text { norfloxacin, ofloxacin }\end{array}$ & \\
\hline Sulfonamides & $\begin{array}{l}\text { sulfadiazine, sulfadimethoxine, } \\
\text { sulfadimidine, sulfathiazole, } \\
\text { sulfachlorpyridazine, sulfaqui- } \\
\text { noxaline, sulfamethoxydiazine }\end{array}$ & $\begin{array}{l}\text { sulfaguanidine, sulfamerazine, } \\
\text { sulfadimethoxazole, sulfa- } \\
\text { monomethoxine, sulfanilamide, } \\
\text { sulfamethoxypyridazine }\end{array}$ & \\
\hline Tetracyclines & $\begin{array}{l}\text { tetracycline, oxytetracycline, } \\
\text { doxycycline, chlortetracycline }\end{array}$ & & \\
\hline Nitroimidazoles & $\begin{array}{l}\text { metronidazole, dimetridazole, } \\
\text { ronidazole }\end{array}$ & & \\
\hline Penicillins & amoxicillin & $\begin{array}{l}\text { benzylpenicillin, ampicillin, } \\
\text { phenoxymethylpenicillin, di- } \\
\text { cloxacillin, oxacillin }\end{array}$ & \\
\hline Macrolides & erythromycin, tylosin & $\begin{array}{l}\text { carbomycin, josamycin, kitasa- } \\
\text { mycin, spiramycin, tilmicosin, } \\
\text { mirosamycin, terdecamycin, } \\
\text { tylvalosin }\end{array}$ & \\
\hline Lincosamides & lincomycin & pirlimycin & \\
\hline Polypeptides & colistin & $\begin{array}{l}\text { enramycin, bacitracin, poly- } \\
\text { mixin }\end{array}$ & \\
\hline Diaminopyrimidines & trimethoprim & Ormetoprim & \\
\hline Cephalosporins & & ceftiofur, ceftriaxone & \\
\hline Others & olaquindox & $\begin{array}{l}\text { bicozamycin, avilamycin, phos- } \\
\text { phomycin, tiamulin, valnemu- } \\
\text { lin, virginiamycin }\end{array}$ & \\
\hline Adamantines & amantadine & & rimantadine \\
\hline $\begin{array}{l}\text { Neuraminidase } \\
\text { inhibitors }\end{array}$ & & & oseltamivir, zanamivir \\
\hline
\end{tabular}

National residue monitoring results show that residues of different antihelminthics are present in poultry products, but the detection rate of antihelminthics in poultry products at levels exceeding maximum residue limits (MRL) is very low. The latest reported antihelminthics in poultry and egg products are: cyromazine in poultry meat from China (2012), EU: ivermectin (2008), oxfendazole (2006, 2011), moxidectin (2010) in poultry meat, Canada: ivermectin below MRL and febendazole and morantel in duck and fowl meat (2011-2014). Due to some cases of positive detection for antihelminthics in poultry and products thereof, a medium level of likelihood of occurrence was attributed to all mentioned substances.

\subsubsection{Insecticides}

Many substances are used to control insects in poultry production and normally they are used indirectly; their use complements biosecurity measures. They are used to treat the equipment and premises where the birds are kept. The following insecticide classes are used as in poultry: organophosphorus compounds, carbamates, pyrethrins and pyrethroids. Substances reported as widely used against ectoparasites in poultry are: phoxim, coumaphos, tetrachlorvinphos, chloryphos, stirophos, spynosad, malathion, carbaryl, propoxur, permethrin, deltamethrin, cypermethrin, fenvalerate, cyfluthrin, bifenthrin, gamma (lambda) cyhalothrin. ${ }^{[1,36]}$ Although information is available that these substances are widely distributed in the poultry tissues and could persist in tissues high in fat content (e.g. fat, skin) for a long time, according to USA, EU, Australia, Canada and Brazil results of national residue monitoring programs, there were no detections at the levels above MRLs in poultry in 2005-2014. Specific cases for insecticides used on poultry are: nicotine and fipronil. 
Table 2. Likelihood of occurrence for substances used against parasitic diseases: anticoccidials, antihelminthics and insecticides in poultry and products thereof.

\begin{tabular}{|c|c|c|c|}
\hline Class of substances & High likelihood of occurrence & $\begin{array}{l}\text { Medium likelihood } \\
\text { of occurrence }\end{array}$ & Low likelihood of occurrence \\
\hline Anticoccidials & $\begin{array}{l}\text { maduramicin, monensin, nara- } \\
\text { sin, salinomycin, semduramicin, } \\
\text { lasalocid, decoquinate, dicla- } \\
\text { zuril, nicarbazin, robenidine, } \\
\text { clopidol, halofuginone, toltra- } \\
\text { zuril, amprolium }\end{array}$ & $\begin{array}{l}\text { roxarsone, nitarsone, arsanilic } \\
\text { acid }\end{array}$ & \\
\hline Anthelmintics & & $\begin{array}{l}\text { ivermectin, oxfendazole, mox- } \\
\text { idectin, febendazole, morantel }\end{array}$ & \\
\hline Insecticides & & nicotine, fipronil & $\begin{array}{l}\text { phoxim, coumaphos, tetrachlor- } \\
\text { vinphos, chloryphos, stirophos, } \\
\text { spynosad, malathion, carbaryl, } \\
\text { propoxur, permethrin, deltame- } \\
\text { thrin, cypermethrin, fenvalerate, } \\
\text { cyfluthrin, bifenthrin, gamma } \\
\text { (lambda) cyhalothrin }\end{array}$ \\
\hline
\end{tabular}

Cotinine, a nicotine metabolite, was reported in Germany in 2012-2014 in poultry meat without a clear explanation of origin. Special attention should be also paid to fipronil as it is often used even though its administration is illegal. ${ }^{[13]}$

Taking into account that normally insecticides are used indirectly to complement biosecurity measures the likelihood of occurrence for those substances could be characterized as low, except nicotine and fipronil, for which it is characterized as medium.

\subsection{Non-steroidal Anti-inflammatory Drugs}

Non-steroidal anti-inflammatory drugs (NSAIDs) have the potential to relieve pain and inflammation without the myriad potential metabolic, hemodynamic, and immunosuppressive adverse effects associated with corticosteroids. ${ }^{[37]}$ Usually non-steroidal anti-inflammatory drugs are used in poultry to reduce stress during transportation or heat shock which could be provoked by increase of environment temperature. At the same time, results of intensive breeding with development of fast growing chickens has resulted in issues with their musculoskeletal system. Leg health of intensively reared broiler chickens is a significant problem. ${ }^{[38,39]}$ NSAIDs could be used to compensate these problems.

Not all the countries include NSAIDs in their national monitoring plans. For substances reported during last year's results of EU monitoring plans: aspirin, carprofen, meloxicam ketoprofen, diclofenac, antipyrin, flunixin, tolfenamic acid were reported in poultry according to results of EU national monitoring plans from year to year, and therefore a high likelihood of occurrence was attributed to all of them. For the substances approved for use in poultry but not included into monitoring plans or never reported: mefenamic acid, naproxen, (oxy) phenilbuthazone, a medium likeli- hood of occurrence was set. Likelihood for non-steroidal anti-inflammatory substances is summarized in Table 3.

\subsection{Performance Enhancers}

There is no history of widespread abuse in poultry for this group of substances ${ }^{[9]}$ but legal requirements and several positive findings show that this group of substances requires attention. Residues of these substances in poultry products could be explained either by illegal practices or by failure to follow good agricultural practices, e.g. cross contamination during feed production or use of medicated feed to non-targeted species. Likelihood of occurrence for performance enhancers is summarized in Table 3.

\subsubsection{Natural and Synthetic Hormonal} Substances, Stilbenes and Resorcylic Acid Lactones

Monitoring results from EU, Canada and USA show that naturally occurring

Table 3. Likelihood of occurrence for non-steroidal anti-inflammatory substances and performance enhancers in poultry and products thereof.

\section{Class of substances \\ Non-steroidal anti-in- \\ flammatory drugs}

Performance enhancers

\section{High likelihood of occurrence}

aspirin, carprofen, meloxicam

ketoprofen, diclofenac, antipyrin, flunixin, tolfenamic acid

ractopamine

\section{Medium likelihood of occurrence}

mefenamic acid, naproxen, (oxy) phenilbuthazone

\section{Low likelihood of occurrence}

natural and synthetic hormonal substances (e.g. progesterone, estradiol, nandrolone); stilbenes and resorcylic acid lactones; beta-agonists, others than ractopamin (e.g. isoxsuprin, terbutaline, metoprolol) 
hormones, such as progesterone, estradiol and some others, are regularly detected in poultry meat. The reasons are not always obvious and they could be present due to the birds' physiological state or administration of the hormonal substance. Levels for these substances in the poultry products are not limited by national or international regulations, mostly because after administration the increased levels remain within normal physiological limits. Results of EU national residue monitoring in poultry also show sporadic presence of synthetic steroids such as nandrolone.

While natural hormones are naturally present in birds' tissues, synthetic substances are not approved for use in birds and enter the poultry production system most probably indirectly or due to illegal practice. A low likelihood of occurrence was attributed to this group of veterinary medicinal products.

Detections of stilbenes and resorcylic acid lactones was not reported for poultry products over the past years. The likelihood of occurrence could be characterized as low.

\subsubsection{Beta-agonists}

The situation with beta agonists seems to be more complex than with other classes of performance enhancers. Some countries allow the use of beta agonists in farmed poultry, e.g. Canada allows the use of ractopamin in turkeys, while some others, e.g. EU and China have totally banned these substances in animal production systems. Analyzing national residue monitoring results, there are detections of ractopamin reported in chicken, turkey and game birds in Canada, and isoxsuprin, terbutaline, metoprolol in poultry in EU. A high likelihood of occurrence attributed to ractopamin as its use in birds is approved and low likelihood of occurrence was attributed for the rest of the pharmaceutical substances belonging to this group, as their presence could be explained by indirectly entering the poultry production systems.

\section{Conclusions and Further Steps}

This was the first attempt to make substantiated recommendations for the development of monitoring plans for veterinary medicinal product residues in poultry and products thereof based on published official monitoring results from different countries. Some similarities in residue occurrence in poultry were found, the list of the substances to control was proposed, but the scope of substances and ranking system require further development.

Some classes of residues were not highlighted in this review, e.g. substances which could be used to compensate animal welfare problems in intensive animal production systems. Welfare issues at intensive poultry production systems such as pecking or cannibalism are well known. An understanding of the possible administration and use of pharmaceuticals, which could compensate these issues, such as sedative or antipsychotic substances should be addressed in the future. The information published in regard of their possible use and residue detection in poultry products is controversial.

Extension of the geographical scope of national monitoring results is required to complement the findings. The attribution of the level of likelihood of occurrence was made based on limited criteria and publically available national contaminant monitoring results. Development of statistic substantiation would be beneficial for a better overview of the overall situation.

\section{Acknowledgements}

The authors express their thanks to colleagues from Institute of Food Safety and Analytical Science, Nestle Research Centre, in particular to T. Goldmann, A. Pittet, P. Mottier for sharing their view on ranking of the likelihood of occurrence for contaminants and to $\mathrm{L}$. Racault for reviewing the draft document.

Received: June 21, 2018

[1] EFSA Panel on Biological Hazards (BIOHAZ), EFSA Panel on Contaminants in the Food Chain (CONTAM) and EFSA Panel on Animal Health and Welfare (AHAW), EFSA J. 2012, 10, 2741.

[2] M. Reig, F. Toldra, Meat Sci. 2008, 78, 60.

[3] M. Alagawany, M. R. Farag, M. E. Abdel-hack, K. Dhama, J. Fowler, World's Poult. Sci. J. 2017, 73, 633

[4] Y.-M. Kao, M.-H. Chang, C.-C. Cheng, S.-S Chou, J. Food Drug Anal. 2001, 9, 84.

[5] M. H. Lee, H. J. Lee, P. D. Ryu, Asian-Australas. J. Anim. Sci. 2001, 14, 402.

[6] T. McDougal, 'FAO: Poultry meat market rising', http://www.poultryworld.net/Meat/Articles/ 2017/12/FAO-Poultry-meat-market-rising226759E/, accessed April 5, 2018.

[7] M. J. Zuidhof, B. L. Schneider, V. L. Carney, D. R. Korver, F. E. Robinson, Poult. Sci. 2014, 93, 2970.

[8] The AVIS Consortium, http://www.fao.org/ag/ againfo/programmes/en/empres/gemp/avis/ about.html, accessed January 25, 2018

[9] World Animal Protection, https://www.worldanimalprotection.org.uk/blogs/10-factswhy-we-need-changeforchickens? gclid= COCQ5svAxNICFSEWOwodqgQFXg, accessed January 25, 2018

[10] Food Agricultural Organization of the United Nations, http://www.fao.org/ag/againfo/themes/ en/poultry/ animal_health.html, accessed February 8, 2018.

[11] G. Darko, J. K. Mensah, S. S. Dapaah, J. Odei, Int. J. Food Contam. 2015, 2, 16, https://doi. org/10.1186/s40550-015-0022-2

[12] T. Beyene, J. Vet. Sci. Technol, 2016, 7, 285

[13] M. L. Whitehead, V. Roberts, J. Small Anim. Pract. 2014, 55, 487.

[14] Food Research Institute, University of Wisconsin-Madison, https://fri.wisc.edu/files/ Briefs_File/FRIBrief_VetDrgRes.pdf, accessed February 20, 2018.

[15] S. H. Abou-Raya, A. R. Shalaby, N. A. Salama, W. H. Emam, F. M. Mehaya, J. Food Drug Anal. 2013, 21, 80 .
[16] L. Tian, S. Khalil, S. Bayen, Crit. Rev. Food Sci. Nutr. 2017, 57, 3760

[17] European Union National Residue monitoring Plans, https://ec.europa.eu/food/safety/chemical_safety/vet_med_residues_en, accessed February 20, 2018.

[18] European Union Rapid Alert System for Food and Feed, https://ec.europa.eu/food/safety/ rasff_en, accessed February 20, 2018.

[19] United States Department of Agriculture, Food safety and inspection service, residue sample results - 'Red book', https://www.fsis.usda.gov/ wps/portal/fsis/topics, accessed February 20 , 2018.

[20] Canadian National Chemical Residue Monitoring Program Reports http://www.inspection. gc.ca/food/chemical-residues-microbiology/chemical-residues/eng/1324258929171 /1324264923941, accessed February 20, 2018.

[21] Australian National Residue Surveys Results and publications, http://www.agriculture. gov. au/ag-farm-food/food/nrs/nrs-results-publications, accessed February 20, 2018.

[22] World Organisation for Animal Health (OIE), http://www.oie.int/fileadmin/Home/eng/Our scientific_expertise/docs/pdf/ Eng_OIE_List antimicrobials_May2015.pdf, accessed June 15, 2018.

[23] J. Parry, BMJ 2005, 331(7507), 10.

[24] Washington Post, http://www.washingtonpost. com/wp-dyn/content/article/2005/06/17/AR200 5061701214.html, accessed February 20, 2018

[25] People.cn, http://en.people.cn/90778/8144363. html, accessed February 20, 2018

[26] Agriculture Corner, http://www.agricorner. com/use-of-antiviral-drug-amantadine-in-com mercial-poultry-an-alarm-for-future-strategyon-control-of-avian-influenza-in-the-country/ \#comments, accessed February 20, 2018

[27] Nature Middle East, 'Emerging Science in the Arab World', http://www.natureasia.com/ en/nmiddleeast/article/10.1038/ nmiddleeast.2016.49, accessed February 20, 2018

[28] E.-S. M. Abdelwhab, H. M. Hafez, 'Control of Avian Influenza in Poultry with Antivirals and Molecular Manipulation', https://www. researchgate.net/publication/275829812 Control_of_Avian_Influenza_in_Poultry_with_ Antivirals_and_Molecular_Manipulation, accessed February 20, 2018

[29] J. L. Davis, G. W. Smith, R. E. Baynes, L. A Tell, A. I. Webb, J. E. Riviere, J. Am. Vet. Med. Assoc. 2009, 235, 528.

[30] A. Permin, J. W. Hansen, 'Epidemiology, diagnosis and control of poultry parasites', FAO, 1998

[31] R. E. Quiros-Castaneda, E. Dantan-Gonzales, BioMed Res. Int. 2015, 430610.

[32] V. Kant, P. Singh, P. K. Verma, I. Bais, M. S Parmar, A. Gopal, V. Gupta, Sci. Int. 2013, 1, 261.

[33] T. Lasky, J. Epidemiol. Community Health 2017, 2017, 71, 1.

[34] Public Chemical Registration Information System of Australian Pesticides and Veterinary Drugs Authority, https://portal.apvma.gov.au/ pubcris, accessed February 20, 2018.

[35] Drug Product Database of Government of Canada, https://health-products.canada.cal dpd-bdpp/index-eng.jsp, accessed February 20, 2018.

[36] V. Goetting, K. A. Lee, L. A. Tell, J. Vet. Pharmacol. Ther. 2011, 34, 521.

[37] S. H. Edwards, 'Nonsteroidal anti-inflammatory drugs', The Merck Veterinary Manual.

[38] G. Caplen , G. R. Colborne , B. Hothersall , C. J. Nicol, A. E. Waterman-Pearson, C. A. Weeks, J. C. Murrell, Vet. J. 2013, 196, 477.

[39] G. Caplen, L. Baker, B. Hothersall, D. E. F. McKeegan, V. Sandilands, N. H. C. Sparks, A. E. Waterman-Pearson, J. C. Murrell, Vet. J. 2013, 198,616 